\title{
Erratum to: A method of extending the depth of focus of the high-resolution X-ray imaging system employing optical lens and scintillator: a phantom study
}

\author{
Guang Li', Shouhua Luo ${ }^{1}$, Yuling Yan ${ }^{2}$ and Ning Gu${ }^{1 *}$
}

${ }^{*}$ Correspondence:

guning@seu.edu.cn

${ }^{1}$ School of Biological Science and Medical Engineering,

Southeast University,

Nanjing 210009, China

Full list of author information

is available at the end of the

article

\section{Erratum to: BioMedical Engineering OnLine 2015, 14 (Suppl 1):S15 DOI 10.1186/1475-925X-14-S1-S15}

After publication of this article [1], we became aware that the article type was erroneously given as 'Review', rather than 'Research'. We apologise for this mistake.

\section{Author details}

${ }^{1}$ School of Biological Science and Medical Engineering, Southeast University, Nanjing 210009, China. ${ }^{2}$ Department of Bioengineering, School of Engineering, Santa Clara University, Santa Clara, CA 95053, USA.

The online version of the original article can be found under doi:10.1186/1475-925X-14-S1-S15.

Received: 15 June 2016 Accepted: 15 June 2016

Published online: 04 July 2016

Reference

1. Li G, Luo S, Yan Y, Gu N. A method of extending the depth of focus of the high-resolution X-ray imaging system employing optical lens and scintillator: a phantom study. BioMed Eng Online. 2015;14(Suppl 1):S15. doi:10.1186/1475-925X-14-S1-S15. provided you give appropriate credit to the original author(s) and the source, provide a link to the Creative Commons license, and indicate if changes were made. The Creative Commons Public Domain Dedication waiver (http://creativecommons.org/publicdomain/zero/1.0/) applies to the data made available in this article, unless otherwise stated. 